\title{
Impact of family income and sickle cell disease on the health-related quality of life of children
}

\author{
Julie A. Panepinto $\cdot$ Nicholas M. Pajewski • \\ Lisa M. Foerster · Svapna Sabnis · \\ Raymond G. Hoffmann
}

Accepted: 15 October 2008/Published online: 7 November 2008

(C) The Author(s) 2008. This article is published with open access at Springerlink.com

\begin{abstract}
Purpose The objective of this study was to determine the impact of family income and sickle cell disease on the health-related quality of life (HRQL) of children.

Methods This was a cross-sectional study of children with and without sickle cell disease. Participants completed the PedsQL ${ }^{\mathrm{TM}}$ generic core scales parent-proxy or child self-report questionnaire during a routine clinic visit. HRQL was the primary outcome measured. Family income and sickle cell disease were the primary independent variables of interest.

Results A total of 104 children with sickle cell disease and 74 without disease participated in the study. After adjusting for family income, patient age, and the presence of co-morbidities, children with severe sickle cell disease had increased odds of worse overall HRQL (parent-proxy HRQL report odds ratio [OR] 4.0) and physical HRQL (parent-proxy report OR 5.67, child self-report OR 3.33) compared to children without sickle cell disease.
\end{abstract}

\section{J. A. Panepinto $\cdot$ S. Sabnis $\cdot$ R. G. Hoffmann \\ Department of Pediatrics, The Children's Research Institute \\ of the Children's Hospital of Wisconsin/Medical College \\ of Wisconsin, Milwaukee, WI, USA}

J. A. Panepinto $(\square)$

Department of Pediatrics, Hematology/Oncology/Bone Marrow Transplantation, MFRC, Medical College of Wisconsin, 8701

Watertown Plank Road, Milwaukee, WI 53226, USA

e-mail: jpanepin@mcw.edu

N. M. Pajewski

Section on Statistical Genetics, Department of Biostatistics,

University of Alabama at Birmingham, Birmingham, AL, USA

L. M. Foerster

Illinois School of Professional Psychology, Chicago, IL, USA
Conclusions Children with sickle cell disease have significantly impaired HRQL, even after considering the potential detrimental effect of family income on HRQL. Targeted interventions to improve these children's HRQL are warranted.

Keywords Sickle cell disease .

Health-related quality of life - Socioeconomic factors .

Children · Family income

\section{Abbreviations \\ HRQL Health-related quality of life}

\section{Introduction}

Health-related quality of life (HRQL) is a complex patientreported outcome that provides an assessment of how an illness, its complications, and its treatment affect the patient. It has become increasingly important to measure patient-reported outcomes such as HRQL [1] to evaluate prognostic factors, to identify problems that can be targeted by an intervention, to compare therapies, and to allocate resources.

The HRQL of children with sickle cell disease is generally poor [2-4]. However, the extent to which the disease itself impacts the HRQL of these children is not clear, since these children are at risk for poor HRQL due to other factors, such as low family income. In the United States, children with sickle cell disease are largely African American. It is well known that African American children are more likely to live in poverty and reside in families with lower family income in the United States [5], a risk factor that was found to be associated with worse HRQL in 
healthy, urban school age children [6]. Therefore, it is important to assess the effect of sickle cell disease on HRQL while acknowledging that children with sickle cell disease are likely to be impoverished.

The objective of this study was to determine the impact of family income and sickle cell disease on the HRQL of children. Our hypothesis was that children with sickle cell disease have worse HRQL than children without sickle cell disease, even after considering the potential detrimental effect of lower family income on HRQL.

\section{Patients and methods}

Study setting and subjects

This was a cross-sectional study conducted from January 2006 through June 2007. Two groups of children aged 2-18 years were eligible for the study: (1) children with sickle cell disease who presented for a routine check-up at the Midwest Sickle Cell Center (MSCC) clinic and (2) children without sickle cell disease who presented for a routine check-up at the Downtown Health Center in Milwaukee, Wisconsin. Children were excluded from the study if they had an acute illness or were hospitalized within the last month.

The MSCC serves over 300 children with sickle cell disease and is based within an academic children's hospital. The Downtown Health Center is an urban-based clinic that provides primary care to over 4,000 children a year. The majority of patients who regularly attend this clinic are African American (80\%) and have public insurance (34\% Medicaid, 58\% Medicaid-HMO).

The demographic data were parent-reported or obtained from the child's medical record. Race data for the children was collected using a modified United States Census classification and reflect parent report based on the following choices: White, Black, native Hawaiian or other Pacific Islander, Asian, American Indian or Alaskan native, other or unknown.

The Institutional Review Board of the Children's Hospital of Wisconsin/Medical College of Wisconsin approved the study. Informed consent was obtained from the parent and assent from children 7 years of age or older.

\section{Primary outcome}

The primary outcome was HRQL measured with the PedsQL ${ }^{\mathrm{TM}}$ generic core scales parent-proxy and child selfreport questionnaire. The PedsQL is a 23 -item generic HRQL questionnaire that has a parent-proxy report for children aged 2-18 years and a child self-report questionnaire for children aged 5-18 years [7]. The questionnaire yields information on the physical, emotional, social, and school functioning of the child during the previous 4 weeks. It has been extensively tested in healthy children [8, 9], children with chronic disease [10-13], and was recently validated in children with sickle cell disease by our group [14]. Mean scores are calculated based on a fivepoint response scale for each item and transformed to a $0-100$ scale, with a higher score representing better quality of life. There are four scale scores: physical functioning, emotional functioning, social functioning, and school functioning. In addition, the PedsQL yields three summary scores: a total scale score, a physical health summary score, and a psychosocial health summary score. The total score is comprised of the average of all items in the questionnaire. The psychosocial summary score is comprised of the average of the items in the emotional, social, and school functioning scales. The physical health summary score is comprised of the average of the items in the physical functioning scale and is the same as the physical functioning scale score. Missing items were handled based on the developer's recommendation, which allows a scale score to be calculated if at least $50 \%$ of the items in each scale are answered [7].

\section{Variables}

Our primary covariates of interest were family income and the presence of sickle cell disease. However, because the severity of sickle cell disease (defined below) [4], age, and the presence of other chronic conditions (medical and neurobehavioral co-morbidities) $[3,4,12,15,16]$ could also affect HRQL, we also examined the effect of these variables on HRQL.

\section{Family income}

The parents/primary caregivers were asked to provide their total household income on a categorical scale for the family income variable. For those respondents that did not provide a family income $(n=41)$, the median household income within their census block group utilizing street addresses was used as a proxy for their income level. The census block group was identified using the U.S. Census Bureau's American Fact Finder. Data from the 2000 Census Summary File 3 were downloaded for each of the block groups identified. Census data were merged with survey data by block group.

Family income was then categorized into three groups $(<\$ 20,000, \$ 20,000-40,000$, and $>\$ 40,000)$, based on work done in a prior evaluation of HRQL and income [6]. We used $\$ 20,000$ as our lowest category of family income, which is consistent with the weighted average 2006 poverty threshold $(\$ 20,614)$ for a family of four (representing 
household income where all members living in the home are included, i.e., three adults and one child, one adult and three children) [5].

\section{Disease severity}

For children with sickle cell disease, disease status was classified a priori as mild or severe disease, regardless of the child's sickle cell disease type, which is consistent with how we have classified disease severity in our prior work $[14,17]$. Children with a history of a sickle cell-related stroke, acute chest syndrome, three or more hospitalizations for vasoocclusive painful events in the prior 3 years, and/or recurrent priapism were classified as having severe disease based on criteria used for intervention with hydroxyurea or bone marrow transplantation [18-20]. All others were classified as having mild disease. The type of sickle cell disease (hemoglobin SS versus SC, etc.) was not used as a marker of disease severity, as it is well known that there is inherent variability in the phenotypic expression and disease manifestations within particular sickle cell genotypes. Because HRQL is meant to reflect the well being and functioning of individuals, it is the experience of disease complications and morbidity in individuals that more accurately reflects their disease status and the potential impact that this will have on HRQL.

\section{Other chronic conditions}

Parents were asked to report whether they had ever been told by a health care provider that their child had any of the following medical conditions: asthma, chronic allergies/ sinus trouble, chronic orthopedic/bone/joint problems, chronic rheumatic disease, diabetes, epilepsy, or other chronic medical condition. Patients were classified as having a medical co-morbidity if they reported one or more of the above chronic medical conditions.

In addition, parents were asked to report whether they had ever been told by a health care provider that their child had any of the following neurobehavioral conditions: anxiety, attentional or behavioral problems, depression, developmental delay or mental retardation, learning problems, or speech problems. Patients were classified as having a neurobehavioral co-morbidity if they reported one or more of the above-noted neurobehavioral conditions.

Age

Age was examined using the age categories of the PedsQL questionnaire: 2-4 years, 5-7 years, 8-12 years, and 13-18 years.
Statistical analysis

Descriptive statistics were used to compare the distribution of demographic factors between children with and without sickle cell disease. Continuous factors were compared using two-sample $t$-tests and non-parametric Wilcoxon rank-sum tests, where appropriate. Categorical factors were compared using Chi-square tests and Fisher-FreemanHalton tests, where appropriate.

To examine the combined effects of sickle cell severity and family income adjusted for medical co-morbidities, neurobehavioral co-morbidities, and age on HRQL, each scale or subscale was divided into categories of impairment based on published population data from Varni et al. [9]. This categorization was performed because of skewed outcome distributions in the presence of ceiling effects, especially amongst the control population. Varni et al. define an impaired HRQL score as less than the population mean -1 standard deviation (SD). Thus for each scale, the mean and SD were used to produce four categories of decreasing impairment: highly impaired $(\leq$ mean $-2 \mathrm{SD})$, impaired ( $>$ mean $-2 \mathrm{SD}$ but $\leq$ mean $-1 \mathrm{SD}$ ), average ( $>$ mean $-1 \mathrm{SD}$ but $\leq$ mean), and above average ( $>$ mean). For example, in the case of the parent-proxy report total score, this led to cutpoints at scores of 49.50, 65.42, and 81.34 on the 100 -point scale. An ordinal logistic regression model was then fitted to the scale outcome with disease group, disease severity, family income, and the presence of medical and neurobehavioral co-morbidities as independent predictors. The presented odds ratios (OR) from the ordinal logistic regression model represent the odds of scoring lower on the ordinal scale, implying worse HRQL.

The imputation of family income based on census data for the 41 respondents with missing income has the potential to bias our results. Consequently, we examined models with missing data as a separate poverty category to test whether the missing data had any effect on the results. Since it did not, we only present the results with the imputed data in the results section.

Predicted probabilities of impaired HRQL ( $\leq$ population mean $-1 \mathrm{SD}$ ) were calculated using the fitted values from the ordinal logistic regression models. All analyses were performed using SAS v9.1.3 (SAS Inc., Cary, NC). An alpha level of 0.05 was used throughout to denote statistical significance.

\section{Results}

Study population

We recruited a convenience sample of patients from both clinics (Fig. 1). Thirty-three subjects with sickle cell 


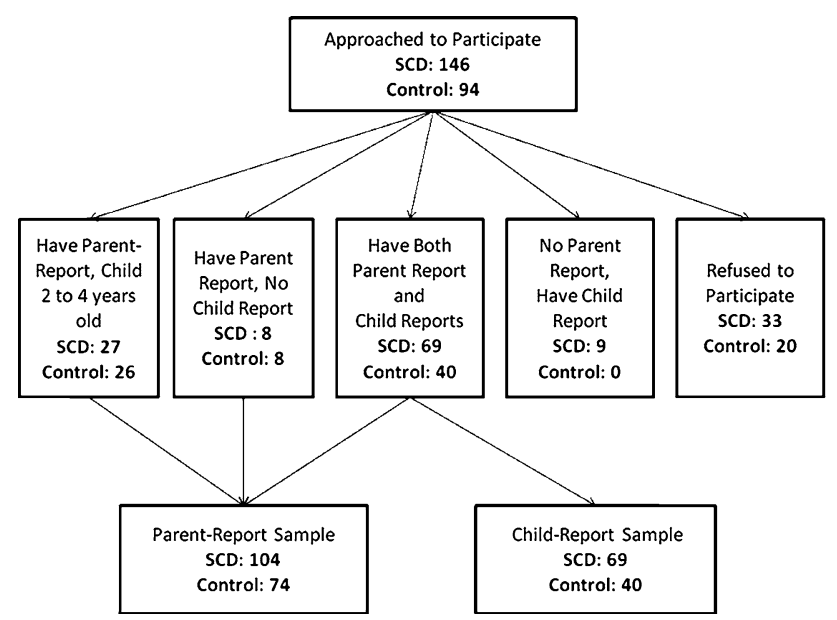

Fig. 1 Description of the available PedsQL parent-proxy reports and child self-reports for children with sickle cell disease (SCD) and control populations

disease refused participation in the study, mostly due to not having an interest in participating or stating that they did not have time to participate. Nine children completed a child self-report of the PedsQL but the parent did not.

Twenty subjects without sickle cell disease refused to participate, again due to the lack of interest or not having time for the study. Our final sample size was 178 subjects; 104 with sickle cell disease and 74 without sickle cell disease.

Parent and child demographics

The majority of parents in both groups were African American, although the parents of children with sickle cell disease were more likely to be African American compared to the parents of children without sickle cell disease (Table 1). In addition, parents of children without sickle cell disease had a higher percentage of reporting the lowest family income (Table 1). Children with sickle cell disease had the following types of sickle cell disease: 66 hemoglobin SS, 26 hemoglobin SC, nine hemoglobin $\mathrm{S} \beta^{+}$, one hemoglobin $\mathrm{S} \beta^{0}$, and two other sickle cell disease variants.

Asthma was the most common medical co-morbidity reported for children in both groups, while attentional and behavioral problems were the most common neurobehavioral co-morbidity (Table 2). The children without sickle cell disease reported more medical co-morbidities than the group of children with sickle cell disease (Table 2).

HRQL: parent-proxy (for children aged $2-18$ years) and child self-report (for children aged 5-18 years)

We have previously published the reliability, feasibility, and HRQL summary and scale scores in these populations showing very little missing data and the poor HRQL of children with sickle cell disease compared to children without disease [14]. Briefly, based on the parent-proxy report, children with sickle cell disease displayed significantly lower scores on all three summary scores, as well as on the social functioning and school functioning scale scores. In contrast, for the child self-reports, children with sickle cell disease only reported significantly lower scores for the physical health summary score [14].

Children with sickle cell disease have worse HRQL than children who do not have sickle cell disease after accounting for family income

\section{Parent-proxy $H R Q L$}

When the effect of sickle cell disease on HRQL was examined taking into account other potential risk factors, children with severe sickle cell disease had a 4.00 times higher odds of having worse total HRQL. Family income at the lowest income level was also indicative of having worse total HRQL for all children (OR 2.88). Similar to our prior work and that of others in sickle cell disease [3, 4], having other co-morbidities and being of older age were also associated with worse HRQL (Table 3).

When the data were further examined by looking at the effect of these covariates on the physical HRQL summary score, children with sickle cell disease had an increased odds of worse physical HRQL. Likewise, having medical co-morbidities, being of older age, and lower family income were also associated with worse physical HRQL.

When examining psychosocial HRQL, children with sickle cell disease had an increased odds of a worse psychosocial HRQL independent of the other co-variates. In addition, older children and having medical or neurobehavioral co-morbidities were associated with worse psychosocial HRQL.

To test whether disease differentially affects HRQL across poverty levels, we also examined models including interaction terms for disease group and poverty level. Since none of the interactions were significant, the detailed results are not shown.

\section{Child self-report $H R Q L$}

When the child self-report of HRQL was examined for the effect of sickle cell disease in the regression model taking into account the other variables, children with severe sickle cell disease had a 3.33 times increased odds of having worse physical HRQL. Unlike in the parent-proxy report of HRQL, none of the variables considered displayed a significant effect on psychosocial HRQL in the child self-report sample (Table 4). 
Table 1 Sociodemographic characteristics of the disease and control children
* $P$-value based on the

Wilcoxon rank-sum test

\begin{tabular}{|c|c|c|c|}
\hline Variable & $\begin{array}{l}\text { Children with } \\
\text { sickle cell disease }\end{array}$ & $\begin{array}{l}\text { Children without } \\
\text { sickle cell disease }\end{array}$ & $P$-value \\
\hline \multicolumn{4}{|c|}{ Parent-proxy report total sample } \\
\hline$n$ & 104 & 74 & - \\
\hline \multicolumn{3}{|l|}{ Age (years) } & 0.036 \\
\hline $2-4$ & $27(26.0)$ & $26(35.1)$ & \\
\hline $5-7$ & $14(13.5)$ & $15(20.3)$ & \\
\hline $8-12$ & $26(25.0)$ & $21(28.4)$ & \\
\hline $13-18$ & $37(35.6)$ & $12(16.2)$ & \\
\hline \multicolumn{3}{|l|}{ Gender } & 0.374 \\
\hline Male & $52(50.0)$ & $32(43.2)$ & \\
\hline \multicolumn{3}{|l|}{ Race/ethnicity } & $<0.001$ \\
\hline African American & $98(94.2)$ & $58(78.4)$ & \\
\hline Other & $1(1.0)$ & $14(18.9)$ & \\
\hline Unreported & $5(4.8)$ & $2(2.7)$ & \\
\hline \multicolumn{3}{|l|}{ Disease status } & - \\
\hline Mild disease & $50(48.1)$ & - & \\
\hline Severe disease & $54(51.9)$ & - & \\
\hline \multicolumn{3}{|c|}{ Parent-reported family income level } & 0.016 \\
\hline$>\$ 40,000$ & $22(21.2)$ & $5(6.8)$ & \\
\hline$>\$ 20,000$ and $\leq \$ 40,000$ & $26(25.0)$ & $13(17.6)$ & \\
\hline$\leq \$ 20,000$ & $36(34.6)$ & $35(47.3)$ & \\
\hline Unknown & $20(19.2)$ & $21(28.4)$ & \\
\hline \multicolumn{4}{|c|}{ Median census household income } \\
\hline Mean \pm SD & $28,678 \pm 1,143$ & $27,798 \pm 1,557$ & $0.253 *$ \\
\hline \multicolumn{4}{|l|}{ Child self-report total sample } \\
\hline$n$ & 69 & 40 & - \\
\hline \multicolumn{3}{|l|}{ Disease status } & - \\
\hline Mild disease & $26(37.7)$ & - & \\
\hline Severe disease & $43(62.3)$ & - & \\
\hline \multicolumn{3}{|c|}{ Parent-reported family income level } & 0.037 \\
\hline$>\$ 40,000$ & $18(26.1)$ & $2(5.0)$ & \\
\hline$>\$ 20,000$ and $\leq \$ 40,000$ & $19(27.5)$ & $9(22.5)$ & \\
\hline$\leq \$ 20,000$ & $21(30.4)$ & $16(40.0)$ & \\
\hline Unknown & $11(15.9)$ & $13(32.5)$ & \\
\hline
\end{tabular}

and a medical co-morbidity (50 points) represent the highest risk group (305 points summed). Using the total points assessed of 305 on the total points line, they would have approximately an $80 \%$ predicted probability (bottom line) of having an impaired physical HRQL. On the other hand, if a child has only mild sickle cell disease (50 points) but is from the lowest family income group ( 80 points), is in the lowest age group ( 0 points), has no neurobehavioral co-morbidities ( 0 points), and also has asthma (a medical co-morbidity -50 points), the predicted probability (from the total of 180 points) of having an impaired physical HRQL is reduced to roughly $43 \%$. It is important to note that we have, for simplicity, omitted estimates of the variability surrounding the predicted probabilities. As discussed by Iasonos et al. [21], it is possible that two 
individuals with the same predicted probability have differential variability surrounding that estimate, depending on the components of the risk. Therefore, if such models

Table 2 Medical and neurobehavioral co-morbidities of disease and control children

$\begin{array}{lll}\begin{array}{l}\text { Sickle cell } \\ \text { disease } \\ (n=104)\end{array} & \begin{array}{l}\text { Controls } \\ (n=74)\end{array} & P \text {-value } \\ & & \end{array}$

\begin{tabular}{|c|c|c|c|}
\hline \multicolumn{4}{|l|}{ Medical co-morbidities } \\
\hline Any & $27(26.0)$ & $35(47.3)$ & 0.003 \\
\hline Asthma & $20(19.2)$ & $28(37.8)$ & \\
\hline Chronic allergies & $6(5.8)$ & $11(14.9)$ & \\
\hline Diabetes & $1(1.0)$ & $1(1.4)$ & \\
\hline $\begin{array}{l}\text { Chronic orthopedic, bone, or } \\
\text { joint problems }\end{array}$ & $9(8.7)$ & $3(4.1)$ & \\
\hline Epilepsy & $4(3.9)$ & $1(1.4)$ & \\
\hline Rheumatic disease & $1(1.0)$ & $0(0.0)$ & \\
\hline Other & $2(1.9)$ & $5(6.8)$ & \\
\hline \multicolumn{4}{|l|}{ Neurobehavioral co-morbidities } \\
\hline Any & $42(40.4)$ & $35(47.3)$ & 0.359 \\
\hline Anxiety problems & $6(5.8)$ & $9(12.2)$ & \\
\hline Attentional problems & $24(23.1)$ & $18(24.3)$ & \\
\hline Behavioral problems & $20(19.2)$ & $18(24.3)$ & \\
\hline Depression & $8(7.7)$ & $6(8.1)$ & \\
\hline $\begin{array}{l}\text { Developmental delay or mental } \\
\text { retardation }\end{array}$ & $4(3.9)$ & $7(9.5)$ & \\
\hline Learning problems & $21(20.1)$ & $14(18.9)$ & \\
\hline Speech problems & $10(9.6)$ & $10(13.5)$ & \\
\hline
\end{tabular}

are to be used as a prognostic tool for identifying children with sickle cell disease at risk for impaired HRQL, this variability will need to be accounted for in the future.

\section{Discussion}

The impact of sickle cell disease on the HRQL of children is apparent, despite whether the children are living in homes with the lowest family income. Because many of these children do live in poverty and have other medical or neurobehavioral co-morbidities in addition to sickle cell disease, the impact of sickle cell disease on HRQL is even more severe. There are no similar chronic diseases that primarily affect those from an impoverished, minority background and our findings highlight how this uniquely affects children with sickle cell disease.

Our study is the first that we know of to examine the collective effect of family income and disease severity on the HRQL of children with sickle cell disease. Other markers of income, such as education of the parent and work status, have been examined and are found to have conflicting results on HRQL in children with sickle cell disease $[3,4]$. However, this prior work has shown the negative effect that disease severity has on the HRQL of the child with sickle cell disease $[3,4,17]$. Because sickle cell disease predominately affects African Americans who are likely to have lower family income [5], it was important to examine the impact of sickle cell disease and family income on the HRQL of these children. Although our

Table 3 Ordinal logistic regression for PedsQL parent-proxy report

\begin{tabular}{|c|c|c|c|c|c|c|}
\hline \multirow[t]{2}{*}{ Outcome } & \multicolumn{2}{|c|}{ Total score } & \multicolumn{2}{|c|}{ Physical health } & \multicolumn{2}{|c|}{ Psychosocial health } \\
\hline & $\mathrm{OR}^{*}$ & $95 \% \mathrm{CI}$ & $\mathrm{OR}^{*}$ & $95 \% \mathrm{CI}$ & $\mathrm{OR}^{*}$ & $95 \% \mathrm{CI}$ \\
\hline \multicolumn{7}{|l|}{ Age (years) } \\
\hline $2-4$ (referent) & - & - & - & - & - & - \\
\hline $5-7$ & 1.85 & $(0.75,4.75)$ & 1.69 & $(0.68,4.19)$ & 1.51 & $(0.62,3.69)$ \\
\hline $8-12$ & 2.61 & $(1.19,5.75)$ & 2.55 & $(1.13,5.76)$ & 2.63 & $(1.18,5.84)$ \\
\hline $13-18$ & 2.74 & $(1.19,6.29)$ & 2.70 & $(1.13,6.44)$ & 2.42 & $(1.05,5.57)$ \\
\hline \multicolumn{7}{|l|}{ Sickle cell disease } \\
\hline No disease (referent) & - & - & - & - & - & - \\
\hline Mild sickle cell disease & 2.11 & $(1.00,4.43)$ & 2.26 & $(1.05,4.87)$ & 2.27 & $(1.08,4.78)$ \\
\hline Severe sickle cell disease & 4.00 & $(1.92,8.31)$ & 5.67 & $(2.68,11.97)$ & 2.81 & $(1.37,5.77)$ \\
\hline \multicolumn{7}{|l|}{ Family income } \\
\hline$>\$ 40,000$ (referent) & - & - & - & - & - & - \\
\hline$>\$ 20,000$ and $\leq \$ 40,000$ & 1.69 & $(0.72,3.96)$ & 2.78 & $(1.16,6.65)$ & 1.37 & $(0.59,3.19)$ \\
\hline$\leq \$ 20,000$ & 2.88 & $(1.22,6.79)$ & 3.87 & $(1.62,9.26)$ & 2.20 & $(0.94,5.15)$ \\
\hline Medical co-morbidity & 2.30 & $(1.25,4.24)$ & 2.39 & $(1.28,4.47)$ & 3.04 & $(1.62,5.70)$ \\
\hline Neurobehavioral co-morbidity & 1.95 & $(1.07,3.57)$ & 1.34 & $(0.73,2.46)$ & 2.31 & $(1.25,4.27)$ \\
\hline
\end{tabular}

$O R$ odds ratio, $C I$ confidence interval

* The odds ratios denote the odds of scoring lower on the ordinal scale, i.e., the odds of having worse HRQL

Bold denotes statistical significance 
Table 4 Ordinal logistic regression for PedsQL child-self-report

\begin{tabular}{|c|c|c|c|c|c|c|}
\hline \multirow[t]{2}{*}{ Outcome } & \multicolumn{2}{|c|}{ Total score } & \multicolumn{2}{|c|}{ Physical health } & \multicolumn{2}{|c|}{ Psychosocial health } \\
\hline & $\mathrm{OR}^{*}$ & $95 \% \mathrm{CI}$ & $\mathrm{OR}^{*}$ & $95 \% \mathrm{CI}$ & $\mathrm{OR}^{*}$ & $95 \% \mathrm{CI}$ \\
\hline \multicolumn{7}{|l|}{ Age (years) } \\
\hline 5-7 (referent) & - & - & - & - & - & - \\
\hline $8-12$ & 0.41 & $(0.16,1.03)$ & 0.63 & $(0.25,1.60)$ & 0.41 & $(0.15,1.07)$ \\
\hline $13-18$ & 0.43 & $(0.17,1.12)$ & 0.60 & $(0.23,1.53)$ & 0.38 & $(0.15,1.00)$ \\
\hline \multicolumn{7}{|l|}{ Sickle cell disease } \\
\hline No disease (referent) & - & - & - & - & - & - \\
\hline Mild sickle cell disease & 1.99 & $(0.77,5.15)$ & 2.59 & $(0.98,6.84)$ & 1.15 & $(0.42,3.14)$ \\
\hline Severe sickle cell disease & 2.18 & $(0.95,4.99)$ & 3.33 & $(1.39,7.99)$ & 1.80 & $(0.78,4.18)$ \\
\hline \multicolumn{7}{|l|}{ Income level } \\
\hline$>\$ 40,000$ (referent) & - & - & - & - & - & - \\
\hline$>\$ 20,000$ and $\leq \$ 40,000$ & 2.07 & $(0.74,5.78)$ & 1.70 & $(0.60,4.78)$ & 1.95 & $(0.68,5.59)$ \\
\hline$\leq \$ 20,000$ & 2.01 & $(0.72,5.64)$ & 1.62 & $(0.58,4.54)$ & 1.54 & $(0.53,4.53)$ \\
\hline Medical co-morbidity & 1.58 & $(0.77,3.25)$ & 1.19 & $(0.57,2.49)$ & 1.73 & $(0.82,3.65)$ \\
\hline Neurobehavioral co-morbidity & 1.52 & $(0.75,3.09)$ & 1.24 & $(0.60,2.56)$ & 1.39 & $(0.68,2.83)$ \\
\hline
\end{tabular}

Results based on $n=109$; see Fig. 1

$O R$ odds ratio, $C I$ confidence interval

* The odds ratios denote the odds of scoring lower on the ordinal HRQL scale, i.e., the odds of having worse HRQL

Bold denotes statistical significance

control patients had lower family income than our patients with sickle cell disease, we still demonstrated a significant effect of family income on the HRQL of children with sickle cell disease.

Prior work has demonstrated the negative impact of lower socioeconomic status on the HRQL of healthy school children $[6,8,22,23]$. In addition, there has been some work examining the impact of markers of socioeconomic

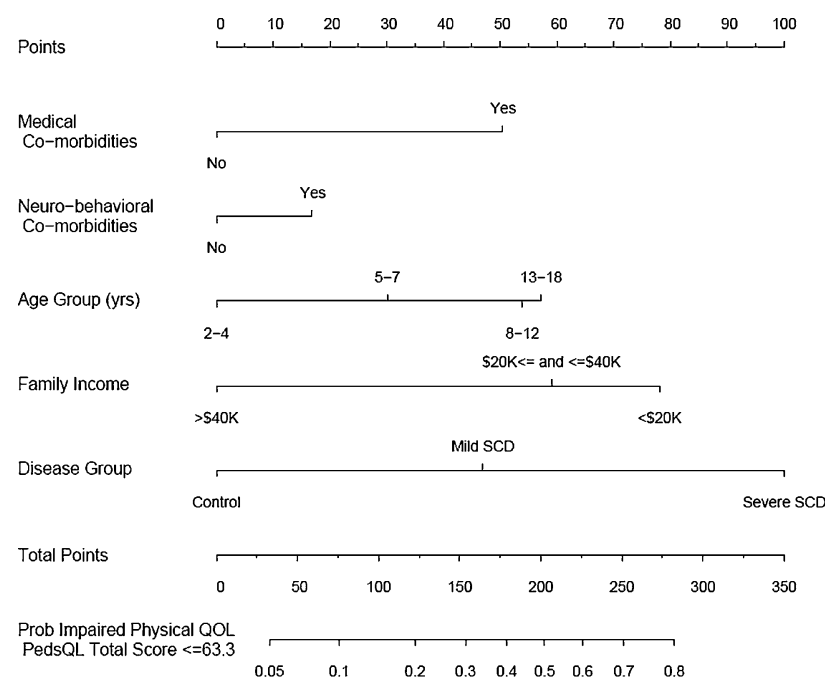

Fig. 2 Nomogram for the predicted probability (which denotes the probability that physical health-related quality of life (HRQL) is $\leq 1$ SD below the population mean reported by Varni et al. [9]) of impaired physical HRQL: parent-proxy report status on the HRQL of children with chronic disease [9, 23-25]. In children with asthma, lower income was a significant, independent predictor of worse HRQL, whereas disease severity was not [24]. Our study found similar results regarding income, but also found the significant impact that sickle cell disease has on the HRQL of these children.

In addition to the impact of poverty, many of the children with sickle cell disease have another co-morbidity, such as asthma or attentional problems, which also affects their well being. The additional challenges of poverty and having other chronic conditions need to be considered in the context of care for these children. As health care providers caring for these children, we have very limited ability to improve their family income. However, future research to determine how treatment for co-morbidities and improvement in disease status affect well being, especially physical well being, are needed as health care providers are able to provide therapy that improves disease status for medical co-morbidities and sickle cell disease.

We did not see the same significant results from the regression models for the parent-proxy and child-selfreports. This may largely be a function of the decreased sample size of child-reports. The point estimates of the odds ratios from each model display the same relationship across both parent-proxy and child-self-reports. However, some degree of disagreement between parent and child reports is not an unexpected result, as there has been consistent evidence indicating that proxy reports of HRQL 
do not necessarily match with child/patient assessments [4, 26, 27]. Two prior studies in children with asthma that utilized child self-report of disease-specific HRQL (but no parent-proxy report of HRQL) found lower socioeconomic status [25] and lower household income [24] to be associated with worse HRQL in children. There are a few prior studies that have utilized both a parent and child self-report of generic HRQL $[8,23]$ and examined the impact of socioeconomic factors. One study using a generic HRQL tool found that chronic disease and a family's financial situation were associated with parent-proxy report of the child's HRQL [23]. However, this study did not find an effect of chronic disease on HRQL in the child self-report but did find an association with the child self-report of HRQL and the family's financial situation [23]. Another study, using the generic PedsQL parent-proxy and child self-reports, found that children with chronic disease had worse HRQL compared to healthy children when socioeconomic status was controlled for in their analysis [8]. This study did not examine the independent effects of both chronic disease and socioeconomic status together. Furthermore, the lack of a disease-specific tool may have prevented us from detecting the impact of disease and family income on the child self-report of HRQL in children with sickle cell disease. In the study by Van Dellen et al. [25] examining asthma, there were no significant associations found between socioeconomic status and generic HRQL, even though, as noted above, they found differences in HRQL by household income when using the diseasespecific asthma measure of HRQL. This study did not report parent-proxy HRQL data. Future research will need to investigate whether disease and poverty do, somehow, differentially affect a child's perception of their HRQL.

Other limitations of our study are its cross-sectional design and that it does not take into account family income over time. Other measures of socioeconomic status were not assessed, such as material deprivation, which may also impact a child's HRQL. In addition, not all families reported their total family income, so census block group data was used to estimate their family income. The census block group data were obtained by utilizing the street address of both groups of children. This method of determining family income has been shown to be valid [28, 29]. Additionally, since the census income did not differ significantly between groups, this should be a reasonable estimate of family income for those families who did not self-report the data. However, because we have more missing data on family income within our control population, our family income data may be biased and may have led to an over or under estimation of the effect of family income. Lastly, we drew our study population from a convenience sample, which may have biased our results and made them less generalizable to other populations.

\section{Conclusions}

In conclusion, children with sickle cell disease have worse health-related quality of life (HRQL) compared to children without sickle cell disease after adjusting for income level and other significant covariates. Older children with severe sickle cell disease who have the lowest family income and other co-morbidities have the worst HRQL.

Acknowledgment This work was supported by grants from the National Institutes of Health (K23 HL80092 and General Clinical Research Center grant M01-RR00058 from the National Center for Research Resources).

Open Access This article is distributed under the terms of the Creative Commons Attribution Noncommercial License which permits any noncommercial use, distribution, and reproduction in any medium, provided the original author(s) and source are credited.

\section{References}

1. Guyatt, G. H., Ferrans, C. E., Halyard, M. Y., Revicki, D. A., Symonds, T. L., Varricchio, C. G., et al. (2007). Exploration of the value of health-related quality-of-life information from clinical research and into clinical practice. Mayo Clinic Proceedings, 82, 1229-1239.

2. Kater, A. P., Heijboer, H., Peters, M., Vogels, T., Prins, M. H., \& Heymans, H. S. (1999). Quality of life in children with sickle cell disease in Amsterdam area. Nederlands Tijdschrift voor Geneeskunde, 143, 2049-2053.

3. Palermo, T. M., Schwartz, L., Drotar, D., \& McGowan, K. (2002). Parental report of health-related quality of life in children with sickle cell disease. Journal of Behavioral Medicine, 25, 269-283. doi:10.1023/A:1015332828213.

4. Panepinto, J. A., O’Mahar, K. M., DeBaun, M. R., Loberiza, F. R., \& Scott, J. P. (2005). Health-related quality of life in children with sickle cell disease: Child and parent perception. British Journal of Haematology, 130, 437-444. doi:10.1111/j.13652141.2005.05622.x.

5. United States Census Bureau. Housing and Household Economic Statistics Division. Poverty Thresholds 2006. Available online at: http://www.census.gov/hhes/www/poverty/threshld/thresh06. html.

6. Mansour, M. E., Kotagal, U., Rose, B., Ho, M., Brewer, D., RoyChaudhury, A., et al. (2003). Health-related quality of life in urban elementary schoolchildren. Pediatrics, 111, 1372-1381. doi:10.1542/peds.111.6.1372.

7. Varni, J. W. (2004). The PedsQL ${ }^{\mathrm{TM}} 4.0$ Measurement Model for the Pediatric Quality of Life Inventory ${ }^{\mathrm{TM}}$ Version 4.0: Administration guidelines. Available online at: http://www.pedsql.org/ pedsqladmin.html.

8. Varni, J. W., Burwinkle, T. M., \& Seid, M. (2006). The PedsQL 4.0 as a school population health measure: Feasibility, reliability, and validity. Quality of Life Research, 15, 203-215. doi:10.1007/ s11136-005-1388-z.

9. Varni, J. W., Burwinkle, T. M., Seid, M., \& Skarr, D. (2003). The PedsQL 4.0 as a pediatric population health measure: Feasibility, reliability, and validity. Ambulatory Pediatrics, 3, 329-341. doi:0.1367/1539-4409(2003)003<0329:TPAAPP $>2.0 . C O ; 2$.

10. Varni, J. W., Burwinkle, T. M., Jacobs, J. R., Gottschalk, M., Kaufman, F., \& Jones, K. L. (2003). The PedsQL in type 1 and 
type 2 diabetes: Reliability and validity of the Pediatric Quality of Life Inventory Generic Core Scales and type 1 Diabetes Module. Diabetes Care, 26, 631-637. doi:10.2337/diacare.26.3.631.

11. Varni, J. W., Burwinkle, T. M., Katz, E. R., Meeske, K., \& Dickinson, P. (2002). The PedsQL in pediatric cancer: Reliability and validity of the Pediatric Quality of Life Inventory Generic Core Scales, Multidimensional Fatigue Scale, and Cancer Module. Cancer, 94, 2090-2106. doi:10.1002/cncr.10428.

12. Varni, J. W., Burwinkle, T. M., Rapoff, M. A., Kamps, J. L., \& Olson, N. (2004). The PedsQL in pediatric asthma: Reliability and validity of the Pediatric Quality of Life Inventory generic core scales and Asthma Module. Journal of Behavioral Medicine, 27, 297-318. doi:10.1023/B:JOBM.0000028500.53608.2c.

13. Varni, J. W., Seid, M., Smith Knight, T., Burwinkle, T., Brown, J., \& Szer, I. S. (2002). The PedsQL in pediatric rheumatology: Reliability, validity, and responsiveness of the Pediatric Quality of Life Inventory Generic Core Scales and Rheumatology Module. Arthritis and Rheumatism, 46, 714-725. doi:10.1002/ art.10095.

14. Panepinto, J. A., Pajewski, N. M., Foerster, L. M., \& Hoffmann, R. G. (2008). The performance of the PedsQL generic core scales in children with sickle cell disease. Journal of Pediatric Hematology/Oncology, 30, 666-673. doi:10.1097/MPH.0b013e318 $17 \mathrm{e} 4 \mathrm{a} 44$.

15. Sawyer, M. G., Reynolds, K. E., Couper, J. J., French, D. J., Kennedy, D., Martin, J., et al. (2004). Health-related quality of life of children and adolescents with chronic illness-A two year prospective study. Quality of Life Research, 13, 1309-1319. doi: 10.1023/B:QURE.0000037489.41344.b2.

16. Valenzuela, J. M., Patino, A. M., McCullough, J., Ring, C., Sanchez, J., Eidson, M., et al. (2006). Insulin pump therapy and health-related quality of life in children and adolescents with type 1 diabetes. Journal of Pediatric Psychology, 31, 650-660. doi: 10.1093/jpepsy/jsj088.

17. Panepinto, J. A., O’Mahar, K. M., DeBaun, M. R., Rennie, K. M., \& Scott, J. P. (2004). Validity of the child health questionnaire for use in children with sickle cell disease. Journal of Pediatric Hematology/Oncology, 26, 574-578. doi:10.1097/01.mph. 0000136453.93704.2e.

18. Charache, S., Terrin, M. L., Moore, R. D., Dover, G. J., Barton, F. B., Eckert, S. V., et al. (1995). Effect of hydroxyurea on the frequency of painful crises in sickle cell anemia. Investigators of the Multicenter Study of hydroxyurea in sickle cell anemia. The New England Journal of Medicine, 332, 1317-1322. doi: 10.1056/NEJM199505183322001.

19. Scott, J. P., Hillery, C. A., Brown, E. R., Misiewicz, V., \& Labotka, R. J. (1996). Hydroxyurea therapy in children severely affected with sickle cell disease. The Journal of Pediatrics, 128, 820-828. doi:10.1016/S0022-3476(96)70335-9.

20. Walters, M. C., Patience, M., Leisenring, W., Eckman, J. R., Scott, J. P., Mentzer, W. C., et al. (1996). Bone marrow transplantation for sickle cell disease. The New England Journal of Medicine, 335, 369-376. doi:10.1056/NEJM199608083350601.

21. Iasonos, A., Schrag, D., Raj, G. V., \& Panageas, K. S. (2008). How to build and interpret a nomogram for cancer prognosis. Journal of Clinical Oncology, 26, 1364-1370. doi:10.1200/ JCO.2007.12.9791.

22. von Rueden, U., Gosch, A., Rajmil, L., Bisegger, C., \& RavensSieberer, U. (2006). Socioeconomic determinants of health related quality of life in childhood and adolescence: Results from a European study. Journal of Epidemiology and Community Health, 60, 130-135. doi:10.1136/jech.2005.039792.

23. Felder-Puig, R., Baumgartner, M., Topf, R., Gadner, H., \& Formann, A. K. (2008). Health-related quality of life in Austrian elementary school children. Medical Care, 46, 432-439.

24. Erickson, S. R., Munzenberger, P. J., Plante, M. J., Kirking, D. M., Hurwitz, M. E., \& Vanuya, R. Z. (2002). Influence of sociodemographics on the health-related quality of life of pediatric patients with asthma and their caregivers. The Journal of Asthma, 39, 107-117. doi:10.1081/JAS-120002192.

25. Van Dellen, Q. M., Stronks, K., Bindels, P. J., Ory, F. G., Bruil, J., \& Van Aalderen, W. M. (2007). Health-related quality of life in children with asthma from different ethnic origins. The Journal of Asthma, 44, 125-131. doi:10.1080/02770900601182459.

26. Varni, J. W., Limbers, C. A., \& Burwinkle, T. M. (2007). Impaired health-related quality of life in children and adolescents with chronic conditions: A comparative analysis of 10 disease clusters and 33 disease categories/severities utilizing the PedsQL 4.0 Generic Core Scales. Health and Quality of Life Outcomes, 5 , 43. doi:10.1186/1477-7525-5-43.

27. Sprangers, M. A., \& Aaronson, N. K. (1992). The role of health care providers and significant others in evaluating the quality of life of patients with chronic disease: A review. Journal of Clinical Epidemiology, 45, 743-760. doi:10.1016/0895-4356 (92)90052-O.

28. Cherkin, D. C., Grothaus, L., \& Wagner, E. H. (1992). Is magnitude of co-payment effect related to income? Using census data for health services research. Social Science and Medicine, 34, 3341. doi:10.1016/0277-9536(92)90064-W.

29. Krieger, N. (1992). Overcoming the absence of socioeconomic data in medical records: Validation and application of a censusbased methodology. American Journal of Public Health, 82, 703710 . 